\title{
Utilization of maternal health services and determinants of skilled care during delivery in slums of Gujarat, India
}

\author{
Miteshkumar Narshinbhai Bhanderi ${ }^{1}$, Kannan Srinivasan ${ }^{2}$ \\ ${ }^{1}$ Medical Office, Health Department, Panchayat, Rajkot, Government of \\ Guajrat, India \\ ${ }^{2}$ AMCHASS, Sree Chitra Tirunal Institute for Medical Sciences and Technology, \\ Trivandrum, Kerala, India
}

Correspondence should be addressed to: Miteshkumar Narshinbhai Bhanderi; mnbhanderi@gmail.com

Received date: 24 April 2014; Accepted date: 10 August 2014; Published date: 8 June 2015

Academic Editor: Zohra S. Lassi

Copyright (C) 2015. Miteshkumar Narshinbhai Bhanderi, Kannan Srinivasan. Distributed under Creative Commons CC-BY 4.0

\begin{abstract}
Background: In India one in three women is delivering without skilled care. This is happening even after the Safe Motherhood Initiative began two decades ago. Aim \& Objective: The aim of the present paper is to assess utilization of maternal health services and factors affecting skilled delivery care among urban slum women. Method: We selected 562 women delivered two year prior to survey using two stage clusters sampling for a community based cross sectional study. Using a pre-tested structured interview schedule, information was collected on demographics, socioeconomic status, use of maternal health services, and reasons for non-utilization of health services. Univariate and multivariate analysis were performed. Result: Majority (92\%) of women received at least one antenatal care during pregnancy, while only 4 out of five women sought skilled care during the last delivery. Women of educationally and socially backward classes (OR=0.46, 95\% CI 0.23 $0.94)$, women live in a distance more than two kilometers from maternity health facility (OR $=0.38,95 \%$ CI $0.22-0.65)$, and women been on their second pregnancy $(\mathrm{OR}=0.44,95 \%$ CI 0.21-0.94) utilized less of skilled care during delivery compared to their counterparts. Increase in education level of women and number of Antenatal care received were tending more utilization of skilled care during delivery. Minimal sense of need, cost, social barriers and perceptions about care were found to be the reasons for not seeking care. Poor attitude of providers, poor quality of services and long waiting time were found to be the reasons for non-utilization of public health facilities. Conclusion: The factors determine skilled delivery care were caste affiliation, education, service availability, parity, perceived utility of services and health seeking behaviors. Government institutions were lying underutilized as women do not prefer them for delivery.
\end{abstract}

Keywords: Maternal Health services, Antenatal care (ANC), Skilled delivery care, Health Seeking behavior, Urban Slum, Gujarat, India

Cite this Article as: Miteshkumar Narshinbhai Bhanderi, Kannan Srinivasan (2015), "Utilization of maternal health services and determinants of skilled care during delivery in slums of Gujarat, India" Obstetrics \& Gynecology: An International Journal, Vol. 2015 (2015), Article ID 293492,

DOI: $10.5171 / 2015.293492$ 


\section{Introduction}

Globally, 289 thousand women die every year during pregnancy or delivery or shortly thereafter; [1] Millennium Development Goals (MDG) aimed at reducing maternal mortality to $75 \%$ of current rate by 2015.[2] Professional attendance during delivery is necessary to reduce maternal mortality; ${ }^{[3]}$ hence, proportion of deliveries by professional or skilled attendant is used as a development indicator. ${ }^{[2]}$ Slow progress towards MDG had led to call for accelerated progress in scaling up of professional delivery care. ${ }^{[4]}$ In the low income countries, one in three pregnant women does not receive health care, $60 \%$ of deliveries do not take place in health facilities, and only about $60 \%$ of all deliveries are attended by a trained staff.[5] According to a national health survey in India, $52 \%$ of pregnant women received three ANCs and only $38 \%$ of deliveries were conducted at health institutions. ${ }^{[6]}$ Whereas in Gujarat, 65\% of pregnant women received three ANCs and $54 \%$ of deliveries were conducted at health institutions. ${ }^{[6]}$ Home deliveries conducted by untrained professional adversely affects infant and mother health.

Home deliveries without skilled care are attributed to many factors such as sociodemographic characteristics such as age, education, ${ }^{[7]}$ fertility, ${ }^{[7,8]}$ socioeconomic status, ${ }^{[9]}$ community affiliation, ${ }^{[10]}$ sociocultural pattern, ${ }^{[10,11]}$ and availability, ${ }^{[12,13]}$ and accessibility of health care services. ${ }^{[14]}$ Socioeconomic status relates to affordability of skilled delivery care; higher cost in delivery is becoming a barrier. ${ }^{[9]}$ Though the services delivered at public institutions are affordable or free for some, at times women had to spend on hidden expenses.[15] Many at times institutional delivery expenses are unpredictable and that becomes a barrier for women to utilize them. ${ }^{[16,17]}$ The choice on the place of delivery is not only determined by patients' income or cost for services, but it is also influenced by the perceived quality of services of an institution. ${ }^{[10,24]}$ In India, socio-cultural factors determine the maternal care; pregnancy and childbirth are viewed as natural processes which require no special attention. It is also found that women belong to lower socio-economic status prefer traditional birth attendants due to socio-cultural proximity.[10] In India childbirth is viewed as a natural event and not due to any illness that requires care from modern medicine. [10]

International Conference on Population Development (ICPD 1994) emphasized the universal access to reproductive health care. In India, even after a decade of ICPD, significant proportion of women still deliver without skilled care because of different reasons. The present study is an attempt to explore utilization pattern of maternal health services and factors influence skilled delivery care among the slum dwellers of Rajkot city. The objectives of the present study are (1) to assess the use of maternal health services among women who delivered in last two years in the slums of Rajkot City, (2) to identify the factors affecting skilled care during delivery.

\section{Methodology}

For the present study we have selected Rajkot city of Gujarat state and followed cross sectional design. The study used a structured interview schedule based on National Family Health Servey-3,[a] UNICEF $^{[b]}$ and unpublished dissertation of MPH[c]. For Consistency, we first translated the schedule into local language and later back translated to English. The schedule was pre-tested in a sub group of women in a slum of Rajkot to test for clarity, validity and reliability of the questions. Later the tool was revised based on results for final use. A sampling unit for this study was the women in household, who delivered in two years prior to study.

Sample size was estimated using Stat Calc of Epi-Info Version (V6). The present study on skilled delivery care was a part of larger study on untreated reproductive morbidity. Hence, for sample size calculation, untreated reproductive morbidity was considered. In a 2001 study, Das et al.,[24] reported untreated reproductive morbidity as $25.7 \%$ and unskilled delivery care as 36 percent in 
a. National Family Health Survey of India (2004-05). b. Multi Indicator Cluster Survey of UNICEF

c. (Un-published thesis work) Equity Effect of Rajasthan Health System Development Project on Utilization of Health services and Unmet Need for Health Care Services: A Case Study from Rajasthan. AMCHSS, SCTIMST, Kerala 2007.

urban slums. Assuming a 50\% greater incidence rate of untreated reproductive morbidity in the present study area, a rate of 38\% was hypothesized. Sample size was calculated to be 513 using Stat Calc V6, with $38 \%$ of untreated reproductive morbidity with a 95\% confidence interval. For the purpose of minimizing the cluster effect, we multiplied the sample size by two. We adopted sampling in two stages. In beginning 45 clusters were selected on random. Subsequently, the households were selected using probability proportionate to size method. Polio campaign list of houses mapped from each ward (smaller divisions within the corporation) by Rajkot Corporation was used as sample frame. As mentioned earlier, the unit of the study was household. It was found that in an average there were 1.25 households per woman. There were 562 eligible women in 826 households. All the 562 were interviewed. The response rate was $100 \%$.

The study was conducted in 2008, with data collection carried out from June 15 to August 31. Using an interview schedule, information regarding demographic and household characteristics, details about their last delivery, care seeking for delivery and various reasons for not seeking care were collected. Data on health facilities available and ward level maps were based on the secondary sources available with the Rajkot Municipal Corporation's Health Department. We entered the data on EpiData 3.1. The analyses were done on SPSS 15.0 .

Initially we have done descriptive statistics of the study samples. The statistical tests done for categorical variables was $\chi^{2}$ analysis; for continuous variables we have done $t$ test. The variables found statistically significant during the bivariate analysis were included in logistic regression model. The variables were regressed to find the contribution of each of them on skilled delivery care. The stepwise entry method was used in binary logistic regression. The significant variables were those variables having $p$ values less than 0.05 .

The data was collected by the community health volunteers from the community. Training was imported to the volunteers based on the National Family Health Survey 3 guidelines. The principal investigator was closely monitoring the data collection.

The Principal Investigator got an ethical clearance by the Institutional Ethical Committee of Sree Chitra Tirunal Institute for Medical Sciences and Technology, Trivandrum. He has also received permission from the health authorities to collect data. The study maintained confidentiality and anonymity throughout the study.

\section{Measurement}

We used the Standard of Living Index of National Family Health Survey 2 for SocioEconomic Status. It is a composite index with the following components: type of house, house ownership, drinking water source, toilet facility, cooking fuel, light source, earning members in the household, size of family, separate kitchen, and number of persons sleep in a room. Skilled care during delivery was operational definition for the proportion of births attended by a skilled health worker ${ }^{[5]}$ in a health facility.

\section{Result}

Respondent Characteristics: In total 826 households were contacted. From those households, 562 women delivered during the two years prior to data collection were interviewed. The results of 562 women are discussed below. The mean age and SLI score of all respondents were $22( \pm 7)$ and $25( \pm 3)$ respectively. The education statuses of the respondents were, $23 \%$ of them were illiterate, and $12 \%$ were able to read or write; $30 \%$ had completed primary education ( 1 to 7 years of 
schooling), $24 \%$ had completed secondary education (8 to 10 years of schooling), and $10 \%$ had completed Higher Secondary education (11 to 12 years of schooling) or above. When we analyzed the occupational statuses, we found $16 \%$ were engaged in paid work. This is a category of women engaged in small businesses, working as servant maids, employed in private or government organizations. The other groups were categorized as unpaid work. This is a category comprised of women whose main engagements in taking care of family and managing household accounts were $84 \%$ of the sample. When data on religious affiliation was analyzed, majority of respondents were Hindus (77\%) followed by Muslims (23\%). The caste distribution showed 51\% respondents belonged to Other Backward Classes, while $18 \%$ belonged to Scheduled Castes/Scheduled Tribes and 31\% were from general caste.

ANC and delivery care received: Among the respondents $30 \%$ of women delivered for first time, 36\% delivered for the second time; and $17 \%$ delivered for the third time and same percentage of them had fourth delivery or more. Majority (92\%) of women had received at least one ANC during pregnancy; $81.5 \%$ received three or more ANC, whereas $7.7 \%$ did not receive any ANC. Among those who received ANC, $59 \%$ of them received from private health care providers, and rest of them received from government health facility. When we enquired the place of last delivery, $25 \%$ of women mentioned government facility, and $45 \%$ said private hospitals; $11 \%$ of women were availing the benefits of "Cheeranjivi Yojna" (a cashless delivery scheme of Government of Gujarat) and 19\% of women delivered at home without any skilled assistance.

Reasons for not using health facilities: When we enquired about the reasons for delivering at home during last delivery, women cited long waiting time(39\%), poor quality of services(30\%), poor provider attitude(31\%), unaffordable $\operatorname{cost}(26 \%)$, health facility was farther(22\%) and not aware of government facility(6\%). Many reported that there was no time to visit hospital because they were not planned earlier. Part of the respondents who delivered at home perceived that child bearing was a normal event and do not require to visit hospital. Few reported that the decision on delivery was not made by them instead by mother in-laws. Some women cited the reason that availability of "dai" - traditional birth attendant was the reason for not visiting the health facility. Some even expressed their apprehension on children being changed in the hospital settings.

In response to why did women not visited government facilities, following reasons were stated: long waiting time (55\%), poor quality of services $(51 \%)$, poor provider's attitude (45\%), long distance (26\%), unfamiliarity with the facilities (3\%), cost $(2 \%)$, lack of trust $(2 \%)$ and denial by family members $(1 \%)$. A few women even stated that there is a belief that women admitted in government hospital die during delivery. As per operational definition, $81 \%$ of births were attended by a skilled health worker at a health facility in last delivery of participants.

Determinants of skilled delivery care: The mean age was lower in skilled delivery care group as compared to those who delivered at home. The mean score of SLI was significantly higher among women who delivered in institutions compared to women did not deliver in institution. The proportion of skilled delivery care was higher in Muslim women and lower in women who engaged paid work. However, this was not statistically significant. Women with higher level of education had significantly higher rates of skilled delivery. While women belong to general caste (92\%) had higher proportion of institutional delivery compared to women from Scheduled caste/Scheduled Tribe (75\%) and Other Backward Class (77\%). The proportion of women with skilled delivery care was decreased significantly with increasing parity. This is evident from the fact that $91 \%$ of women who had first delivery had institutional care, while only $68 \%$ of fourth or higher than fourth delivery had institutional care. The proportion of institutional delivery was 
increasing significantly with increasing in number of ANCs received. Women who had their ANC from private health facility were more likely to be delivered in institutions compared to those who received ANC from government facility. It is also found that skilled care during delivery was more common among women who live nearer to maternity centers. (Table 1)

Table 1: Skilled Delivery Care - Results of bivariate

\begin{tabular}{|c|c|c|c|}
\hline & & $\begin{array}{l}\text { Skilled Care } \\
\text { During } \\
\text { Delivery (\%) }\end{array}$ & $\begin{array}{l}\text { Unadjusted OR } \\
(95 \% \mathrm{CI})\end{array}$ \\
\hline Age & & $25.4^{\mathrm{a}}( \pm 3.9)$ & $0.99(0.94-1.04)$ \\
\hline \multirow[t]{3}{*}{ Caste } & General & $160(92.0)$ & 1 \\
\hline & Schedule Caste \Tribe & $77(75.5)$ & $0.27^{* * *}(0.13-0.54)$ \\
\hline & OBC & $220(76.9)$ & $0.29^{* * *}(0.15-0.53)$ \\
\hline \multicolumn{2}{|c|}{ Standard of Living Index } & $23.1^{\mathrm{a}}( \pm 6.5)$ & $1.12^{* * *}(1.09-1.16)$ \\
\hline \multirow[t]{5}{*}{ Education } & Not able to read or write & $82(62.6)$ & $\overline{1}$ \\
\hline & Able to read or write (Just literate) & $58(82.9)$ & $2.88^{* *}(1.41-5.9)$ \\
\hline & Primary (1-7) & $141(83.4)$ & $3.0^{* * *}(1.75-5.15)$ \\
\hline & Secondary $(8-10)$ & $122(90.4)$ & $5.6^{* * *}(2.86-10.98)$ \\
\hline & Higher Secondary (11-12) and Plus & $54(94.7)$ & $10.7^{* * *}(3.19-36.26)$ \\
\hline \multirow{4}{*}{$\begin{array}{l}\text { Number of } \\
\text { Pregnancy }\end{array}$} & First & $151(91.0)$ & 1 \\
\hline & Second & $164(80.4)$ & $0.4^{* *}(0.21-0.76)$ \\
\hline & Third & $76(79.2)$ & $0.37^{* *}(0.18-0.77)$ \\
\hline & Fourth or more & $66(68.8)$ & $0.21^{* * *}(0.11-0.43)$ \\
\hline \multirow{4}{*}{$\begin{array}{l}\text { Antenatal } \\
\text { Care } \\
\text { Received: }\end{array}$} & Not at all & $12(27.9)$ & $\overline{1}$ \\
\hline & Once & $17(60.7)$ & $3.99^{* * *}(1.45-10.95)$ \\
\hline & Twice & $21(63.6)$ & $4.52^{* * *}(1.7-11.96)$ \\
\hline & Thrice or more & $407(88.9)$ & $20.61^{* * *}(9.96-42.66)$ \\
\hline \multirow{2}{*}{$\begin{array}{l}\text { Maternity } \\
\text { Health } \\
\text { Facility } \\
\end{array}$} & $<2$ kilometers distance & $300(88.2)$ & 1 \\
\hline & $\geq 2$ kilometers distance & $152(70.0)$ & $0.31^{* * *}(0.20-0.48)$ \\
\hline
\end{tabular}

\section{CI- confidence Interval, a-mean value}

After controlling for other variables, SLI [OR=1.12 (95\% CI 1.09-1.16)], belonging to Other Backward Classes caste group [OR=0.46 (95\% CI 0.23-0.94)], more than two kilometers of distance of maternity health facility $[\mathrm{OR}=0.38 \quad(95 \%$ CI 0.22 $0.65)]$, in education 'able to read or write' group [OR=2.46 (95\% CI 1.02-5.91)], 8 to 10 years of education group [OR=2.25 (95\% CI 1.02-4.97)] and 11 and 12 years of education and above group [OR=4.87 (95\% CI 1.2-19.76)], number of ANC care received once $[\mathrm{OR}=4.4 \quad(95 \%$ CI 1.33 14.56)], ANC care received twice [OR=4.77 (95\% CI 1.55-14.68)], ANC received thrice and more [OR=14.82 (95\% CI 6.25-35.11)], and second pregnancies [OR=0.44 (95\% CI 0.21-0.94)] were all found to be significantly associated with skilled care during delivery (Table 2). 
Table 2: Skilled Delivery Care - Results of multivariate analysis

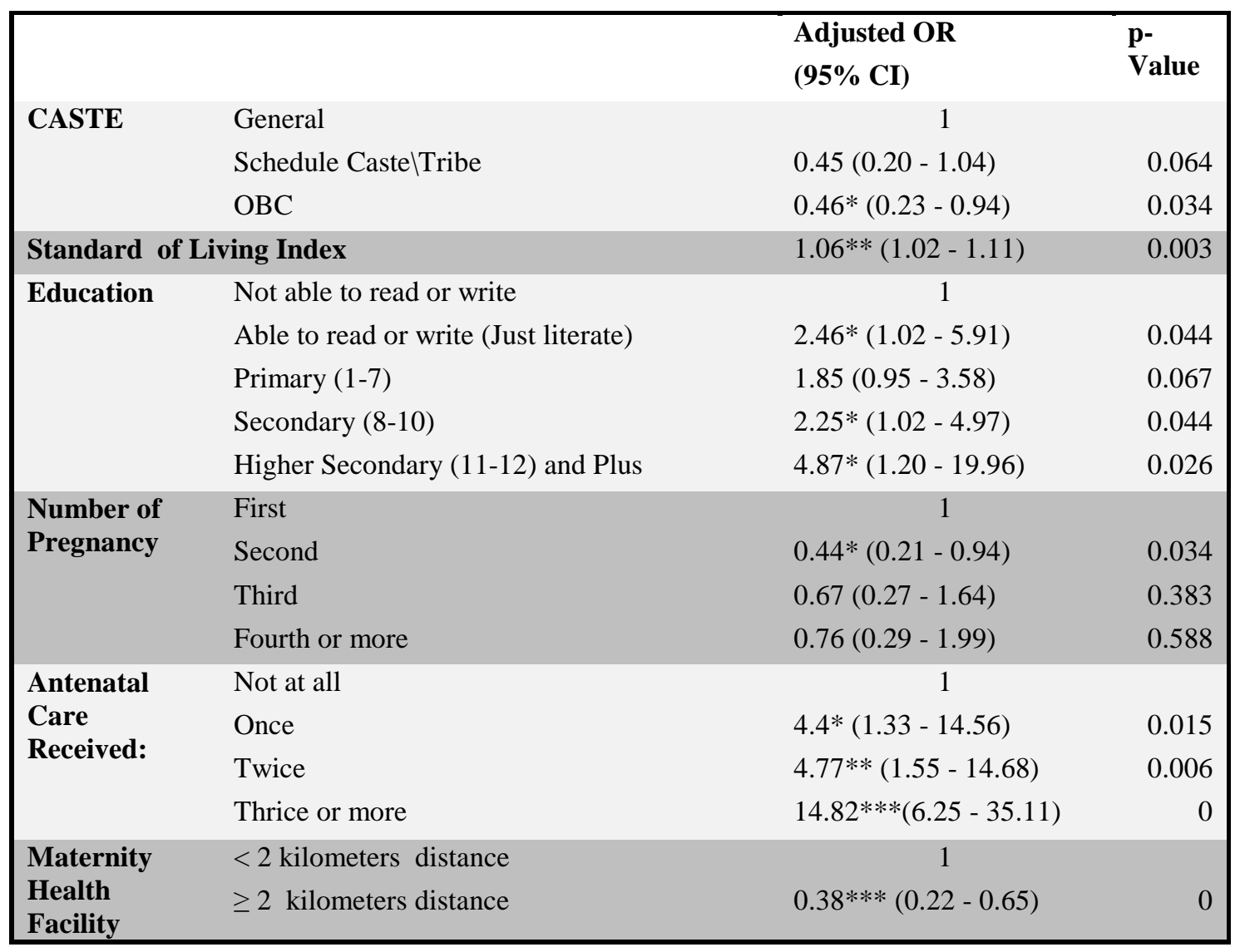

\section{Discussion}

The present study found, high proportion of pregnant women received ANC care and institutional delivery compared to nation as a whole.[6] This could be due to high maternal education, low parity compared to national average, and availability of different types of facilities such as government, None Government Organizations, private and corporation health facility in the site.

A finding on effect of education on maternal health care is in conformation with other studies. ${ }^{[7,8]}$ Education enhances autonomy among women that develops greater confidence and capabilities to make decisions on their own health and in return this influences their health seeking behavior and seek health care. ${ }^{[19,20,24]}$ Other important factor in India is the social stratification. Among the socially disadvantaged and marginalized Scheduled Caste/Scheduled Tribes and Other Backward Castes, skilled care delivery is compromised, as majority of them have low level of education and resources to support. ${ }^{[6,7,24]}$ Further, the traditional practices and cultural factors prevent them from accessing health care. Women from low socioeconomic status have poor access to skilled care during delivery is an established fact. $[9,15,17,20]$ This is may be due to the cost of care, low resource availability, and low perceived need. This is in conformity with our findings.

Influence of number of ANC on choice of place of delivery was as expected.[12,13,21] This may be due to the fact that women with more ANC visits expose to health education and counseling that influences health seeking behavior. This study 
showed women who delivered first pregnancy were more likely to deliver at health facility compared to who delivered second and above. This finding is consistent with other studies.[7,8,19,20] The possible explanation for this is that first delivery considered to be precious and it is perceived that women who were pregnant for the first time are expected to have complications during delivery compared to women who deliver second. This may also due to high parity women develop confidence over time and tend to believe that modern health care was not necessary as they were experienced and have acquired knowledge from first delivery.

The use of health facilities for delivery was compromised when distance was more because it involves availability of transport facilities, transportation cost and time and limited freedom of movement for women. ${ }^{[10,12,13,24]}$

Provider-client relationships had a major effect on the perception on the quality of services, and in turn influence the utilization of delivery care.[10] Rude and harassment behaviors of service providers were the barriers to access and utilization of health services. ${ }^{[22]}$ The majority of women in the present study reported cost of care and distance of health facility as reasons for home deliveries. Many elderly women preferred "dai"-a traditional birth attendant for conducting deliveries, because they were familiar with the cultural norms and their proximity in location.[11] Cultural factors play an important role in health care seeking behavior for delivery among all communities.[23,24] In this study, especially the influence from decision-makers, selfperception and traditional views on delivery were highlighted to be dominant factors that influenced the place of delivery.

Study Limitations: Large sample size and meticulous data collection with close supervision are the strengths of the present study. Further we found the inconsistency and unknown values were very minimal. Detailed information on services availed and availability of facilities of health services were collected. The data collected from urban slums are generalizable to similar slums in India as they are same in terms of presence of migrant residents, living standards, tenure of their jobs and so on. In contrast there are some limitations of the study. The question on the use of maternal health services focused only on the most recent pregnancy/birth in two years preceding the survey, it was not possible to investigate behavioral consistency in the use of these services between successive births from the same woman, and hence it is difficult to establish causal relationship.

\section{Conclusion}

In the study area, although majority of pregnant women seek Antenatal care, but every fifth delivery was not attended by skilled personnel. Social determinants such as socioeconomic status, caste, education, use of Antenatal care, number of pregnancy and distance of maternity health facility were the determinants found to be associated with skilled delivery care. This was further affected by self perception, belief, and lack of felt need. Pregnant women were deviating from public health system to seek care because of providers and health system related problems. The findings on association between the following, education status, caste status, illness duration, maternity health facility distance and SLI and health seeking behavior needs to be addressed by the health authority. There needs to be a strong initiative for poor urban women education. The programs to improve standard of living among Backward and Scheduled Caste and Scheduled Tribe population were not reaching them. This suggests a strong monitoring and controlling of the programs delivering benefits to the needy. In a fast urbanization era the distance of health facilities found to be a significant problem needs immediate attention. Targeted interventions are the only solution for this. Standard of living figures indicate the need for creating employment and income generation activities for urban poor. 


\section{Acknowledgment}

Special acknowledgement to $\mathrm{Dr}$ Amarjit Singh, Principal Secretary and Commissioner, Department of Health and Family Welfare, Government of Gujarat, whose ideas and guidance gave me strength and courage during the study. He was the one who paved the way for the initiation and operationalization of the study. This piece of work would never taken this shape without the help of Dr. Sundari Ravindran, Dr. P. Sankara Sarma ,Dr. V Raman Kutty, Dr. Mala Ramanathan, Dr. Biju Soman and Dr. Manju Nair, faculties of AMCHSS, for their valuable suggestions and guidance in completing my dissertation. I register my thanks to our Director, Prof $\mathrm{K}$ Mohandas and Dr. K.R.Thankappan Head of the Department, for giving me the opportunity and facilities to do this study. Finally, I convey my warm thanks to the women who formed our sample for the study, for responding to the field teams and sharing some intimate details of their lives. Salute to the almighty who created the world, the study subjects and the researcher.

\section{References}

1. WHO, UNICEF, UNFPA, The World Bank and the United Nations Population Division. (May 2014). Trends in Maternal Mortality: 1990 to 2013. [Online]. [Retrieved July 7, 2014], http://www.who.int/reproductivehealth/p ublications/ monitoring/maternalmortality-2013/en/

2. Millenium Development Goals. Washington: World Bank; 2007. Available at: www.developmentgoals.org (Accessed on 31st May 2008).

3. de Bernis L, Sherratt DR, AbouZahr C and Van Lerberghe W. (2003) "Skilled attendants for pregnancy, childbirth and postnatal care," Br Med Bull, (67) 39-57.

4. Lawn JE, Tinker A, Munjanja SP and Cousens S. (2006) "Where is maternal and child health now?," Lancet, (368)1474-7.
5. WHO. Skilled attendant at birth -2006 updates. Geneva: World Health Organization, 2006c. http://www.who.int/reproductivehealth/g lobal_ monitoring/ skilled_attendant.html (accessed July 5, 2008).

6. International Institute for Population Sciences (IIPS). National Family Health Survey (NFHS-3) 2005-06. India, Mumbai http://www.nfhsindia. org/nfhs3.html (Accessed on 14th Feb 2008).

7. Thind A, Mohani A, Banerjee $\mathrm{K}$ and Hagigi F. (2008) "Where to deliver? Analysis of choice of delivery location from a national sample survey in India," $B M C$ Public Health, (8) 29.

8. van Eijk AM, Bles HM, Odhiambo F, Ayisi JG, Blokland IE, Rosen DH, et al. (2006) "Use of Antenatal services and delivery care among women in rural western Kenya: a community based survey," Reprod Health, (3) 2.

9. Borghi J, Ensor T, Somanathan A, Lissner C and Mills A. (2006) "Mobilising financial resources for maternal health," Lancet, (368) 1457-65.

10. Mrisho M, Schellenberg JA, Mushi AK, Obrist B, Mshinda $\mathrm{H}$, Tanner $\mathrm{M}$, et al. (2007) "Factors affecting home delivery in rural Tanzania," Trop Med Int Health, (12) 862-72.

11. Nyanzi S, Manneh $\mathrm{H}$ and Walraven G. (2007) "Traditional Birth Attendants in rural Gambia: beyond health to social Cohesion," Afr J Reprod Health, 11(1) 4356.

12. Mpembeni RN, Killewo JZ, Leshabari MT, Massawe SN, Jahn A, Mushi D, et al. (2007) "Use pattern of maternal health services and determinants of skilled care during delivery in Southern Tanzania: implications for achievement of MDG-5 targets," BMC Pregnancy and Childbirth, (7) 29.

13. Anwar I, Sami M, Akhtar N, Chowdhury ME, Salma U, Rahman M and Koblinsky M. (2008) "Inequity in maternal health-care 
services: evidence from home-based skilled-birth-attendant programmes in Bangladesh," Bull World Health Organ, 86 (4) 252-9.

14. Navaneethama $\mathrm{K}$ and Dharmalingamb A. (2002) "Utilization of maternal health care services in Southern India," Soc Sci Med, 55 (10) 1849-69.

15. Nahar S and Costello A. (1998) "The hidden cost of free maternity care in Dhaka, Bangladesh," Health Policy Plan, (13) 417-22.

16. Borghi J, Hanson $\mathrm{K}$, Acquah CA, Ekanmian G, Filippi V, Ronsmans C, et al. (2003) "Costs of near-miss obstetric complications for women and their families in Benin and Ghana," Health Policy Plan, (18) 383-90.

17. Koenig MA, Jamil K, Streatfield PK, Saha T, Al-Sabir A, El Arifeen S, Hill K and Haque Y. (2007) "Maternal health and careseeking behavior in Bangladesh: findings from a national survey," Int Fam Plan Perspect, 33 (2) 75-82.

18. Bloom SS, Wypij D and Das Gupta M. (2001) "Dimensions of women's autonomy and the influence on maternal health care utilization in a north Indian City," Demography, 38 (1) 67-78.
19. Mekonnen Y and Mekonnen A. (2003) "Factors Influencing the Use of Maternal Healthcare Services in Ethiopia," J Health Popul Nutr, 21 (4) 374-82.

20. Stephenson R, Baschieri A, Clements S, Hennink $M$ and Madise N. (2006) "Contextual Influences on the Use of Health Facilities for Childbirth in Africa," $\mathrm{Am} J$ Public Health, 96 (1) 84-93.

21. Salam A and Siddiqui SA. (2006) "Socioeconomic inequalities in use of delivery care services in India," J Obstet Gynecol India, 56 (2) 123-27.

22. Duong DV, Binns CV and Lee AH. (2004) "Utilization of delivery services at the primary health care level in rural Vietnam," Soc Sci Med, 59 (12) 2585-95.

23. Seljeskog L, Sundby J and Chimango J. (2006) "Factors influencing women's choice of place of delivery in rural Malawian explorative study," Afr J Reprod Health, 10 (3) 66-75.

24. Bhander MN and Srinivasan K. (2010) "Untreated reproductive morbidities among ever married women of slums of Rajkot City, Gujarat: The role of class, distance, provider attitude, and perceived quality of care," J Urban Health, 87 (2) 254 263. 